\title{
1038 Magnetic resonance evaluation of the associations of thoracic and abdominal aortic plaques with the presense and extent of coronary artery stenosis
}

\author{
Yukihiko Momiyama*1, Hiroaki Taniguchi², Zahi A Fayad ${ }^{3}$, Ryuichi Kato², \\ Nobukiyo Tanaka ${ }^{2}$, Reiko Ohmori², Teruyoshi Kihara ${ }^{4}$, Masayoshi Nagata ${ }^{4}$, \\ Haruo Nakamura² and Fumitaka Ohsuzu ${ }^{2}$
}

Address: ${ }^{1}$ National Hospital Organization Tokyo Medical Center, Tokyo, Japan, ${ }^{2}$ National Defense Medical College, Saitama, Japan, ${ }^{3}$ Mount Sinai School of Medicine, New York, NY, USA and ${ }^{4}$ Iruma Heart Hospital, Saitama, Japan

* Corresponding author

from I th Annual SCMR Scientific Sessions

Los Angeles, CA, USA. I-3 February 2008

Published: 22 October 2008

Journal of Cardiovascular Magnetic Resonance 2008, I0(Suppl I):AI63 doi:I0.I I86/I532-429X-10-SI-AI63

This abstract is available from: http://jcmr-online.com/content/I0/SI/AI63

(C) 2008 Momiyama et al; licensee BioMed Central Ltd.

\section{Introduction}

The association between coronary artery disease (CAD) and thoracic aortic plaques was often reported using transesophageal echocardiography. Although an autopsy study reported plaques in abdominal aorta, but not in thoracic aorta, to be severe in patients with cardiac catastrophe, studies showing the association between CAD and abdominal plaques are scarce. Recently, MRI became a useful tool for non-invasively evaluating atherosclerotic plaques in both thoracic and abdominal aortas. Using MRI, we investigated the associations of thoracic and abdominal aortic plaques with the presence and extent of coronary artery stenosis.

\section{Methods}

Aortic MRI was performed on Signa $1.5 \mathrm{~T}$ Cvi with a phased-array body coil in 146 patients undergoing coronary angiography. Transverse PDW and T2W images of thoracic descending and abdominal aortas were obtained using ECG-gated, double-inversion-recovery FSE sequence. Imaging parameters were $\mathrm{TR}=2 \mathrm{RR}$ intervals, $\mathrm{TE}=10(\mathrm{PDW})$ and $60 \mathrm{~ms}(\mathrm{~T} 2 \mathrm{~W}), 20-\mathrm{cm}$ FOV, $4-\mathrm{mm}$ slice thickness, 8-mm inter-slice gap, $256 \times 256$ acquisition matrix, and 32 echo-train. For each patient, 9 slices of thoracic aorta and 9 slices of abdominal aorta were obtained at $12-\mathrm{mm}$ intervals, which each covered about $10-\mathrm{cm}$ por- tion of thoracic aorta below arch and $10-\mathrm{cm}$ portion of abdominal aorta above the bifurcation of iliac artery. Plaque was defined as a clearly identified luminal protrusion with focal wall thickening, and plaque extent in each slice was scored 0 to 4 points by the percentage of luminal surface involved by plaque. Plaque extents in thoracic and abdominal aortas were represented as the number of slices with plaque (plaque slice number) and the sum of scores of 9 slices (plaque extent score). On coronary angiograms, the degree of stenosis in each segment was evaluated by 5 grades. The extent of coronary stenosis was represented as the number of $>50 \%$ stenotic vessels and the numbers of $>50 \%$ and $>25 \%$ stenotic segments.

\section{Results}

Of the 146 patients, 108 had CAD ( $>50 \%$ luminar diameter stenosis) on angiograms. The prevalence of thoracic and abdominal aortic plaques was higher in patients with CAD than without CAD (73\% and $94 \%$ vs. $32 \%$ and $79 \%$, $\mathrm{P}<0.025)$. In multivariate analysis, thoracic plaques were an independent factor for the presence of CAD, while abdominal plaques were not. Of the 108 CAD patients, 47 had 1-vessel, 39 had 2-vessel, and 22 had 3-vessel disease. Stepwise increases in the prevalence and extents of both thoracic and abdominal plaques were found depending on the number of $>50 \%$ stenotic coronary vessels. The 
plaque slice number and extent score in thoracic aorta correlated with the numbers of $>50 \%$ stenotic coronary segments $(\mathrm{r}=0.31$ and 0.30 by Spearman's rank correlation $)$ and $>25 \%$ stenotic segments $(r=0.41$ and 0.41$)(P<$ 0.002). The plaque slice number and extent score in abdominal aorta also correlated with the numbers of $>50 \%$ stenotic segments $(\mathrm{r}=0.39$ and 0.40$)$ and $>25 \%$ stenotic segments $(\mathrm{r}=0.43$ and 0.44$)(\mathrm{P}<0.001)$. Notably, total plaque slice number (a total of plaque slice numbers in thoracic and abdominal aortas) and total plaque extent score (a total of plaque extent scores in aortas) correlated best with the numbers of $>50 \%$ stenotic segments $(\mathrm{r}=0.40$ and 0.41$)$ and $>25 \%$ stenotic segments $(\mathrm{r}=0.49$ and 0.49$)(\mathrm{P}<0.001)$. Total plaque extent was found to be the best predictor for the presence of CAD by receiver-operating-characteristics curve analysis $(\mathrm{P}<$ $0.01)$.

\section{Conclusion}

The prevalence of plaques in both thoracic and abdominal aortas was high in patients with CAD. Although only thoracic plaques were an independent factor for CAD, plaque extents in both thoracic and abdominal aortas correlated with the extent of coronary stenosis. As a result, total aortic plaque extent was more closely associated with the presence and extent of coronary stenosis than thoracic or abdominal plaque extent, and this factor was considered to be the best predictor for CAD.
Publish with Biomed Central and every scientist can read your work free of charge

"BioMed Central will be the most significant development for disseminating the results of biomedical research in our lifetime. " Sir Paul Nurse, Cancer Research UK

Your research papers will be:

- available free of charge to the entire biomedical community

- peer reviewed and published immediately upon acceptance

- cited in PubMed and archived on PubMed Central

- yours - you keep the copyright

Submit your manuscript here:

http://www.biomedcentral.com/info/publishing_adv.asp 